Railway Engineering

July 2021

Issue:14, Page: 167-179

Research Article

doi: 10.47072/demiryolu.944266

http://dergipark.org.tr/demiryolu

e-ISSN: 2687-2463, ISSN: 2149-1607

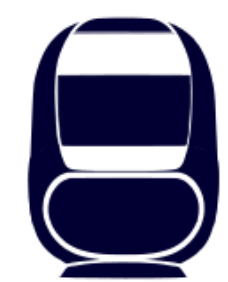

\title{
Termit ve Yakma Alın Kaynağı ile Birleştirilmiş R260 Kalite Rayın Mikroyapı ve Mekanik Özelliklerinin İncelenmesi
}

\author{
Harun ÇUĞ $\breve{G}^{* 1}$, Mustafa DURSUNLAR ${ }^{2}(\mathbb{0}$ \\ ${ }^{1}$ Karabük Üniversitesi, Mühendislik Fakültesi, Makine Mühendisliği Bölümü, Karabük, Türkiye \\ ${ }^{2}$ Yozgat Bozok Üniversitesi, Sorgun Meslek Yüksekokulu, Ulaştırma Hizmetleri Bölümü, Yozgat, Türkiye \\ *hcug@karabuk.edu.tr
}

(Alınış/Received: 28.05.2021, Kabul/Accepted: 24.06.2021, Yayımlama/Published: 31.07.2021)

Öz: Bu çalışmanın amacı rayların birleştirilmesinde kullanılan en yaygın iki yöntem olan termit ve yakma alın ray kaynağı yöntemlerinin mikroyapı ve mekanik özelliklerini incelemektir. Bu çalışmada kullanılan ray EN 13674-1 standarda, R260 kaliteye, 60E1 profile ve $1 \mathrm{~m}$ uzunluğa sahiptir. Belirtilen özelliklerdeki raylar, gerekli çalışmalar için termit ve yakma alın ray kaynăğ yöntemleri ile birleştirilmiştir. Termit ray kaynağı TCDD DATEM'de, yakma alın ray kaynağı ise TCDD Çankırı Makas Fabrikası'nda yaptırılmıştır. Kaynak sonrası termit ve yakma alın kaynaklı rayın, ray mantarından alınan parçaların kalıntı gerilme, mikroyapı, sertlik ve çekme özellikleri incelenmiş̧ir. Kalıntı gerilme sonuçlarına göre, orijinal kaynaksız rayın kalıntı gerilme değeri $154 \mathrm{MPa}$, termit kaynaklı rayın kalıntı gerilme değeri $172 \mathrm{MPa}$ ve yakma alın kaynaklı rayın kalıntı gerilme değeri ise $160 \mathrm{MPa}$ olarak bulunmuştur. Mikroyapı sonuçlarına göre, termit kaynaklı rayın mikroyapısı incelendiğinde, yapının ferrit ve perlit olup, martenzit olmadığ gözlemlenmiş̧ir. Yakma alın kaynaklı rayın mikroyapısı incelendiğinde, yapının çoğunlukla ferrit ile perlitik olduğu gözlemlenmiştir. Sertlik testi sonuçlarına göre, termit ray kaynağındaki sertlik değerleri kaynak merkezinde ortalama 292 HV1, kaynak merkezi ile ITAB arasında ortalama 310 HV1, ITAB'da ortalama $308 \mathrm{HV} 1$, ITAB ile ray metali arasında ortalama $264 \mathrm{HV} 1$ ve ray metalinde ortalama $251 \mathrm{HV} 1$ olarak gözlemlenmiştir. Yakma alın ray kaynağındaki sertlik değerleri, kaynak merkezinde ortalama 296 HV1, kaynak merkezi ile ITAB arasında ortalama 298 HV1, ITAB'da ortalama 292 HV1, ITAB ile ray metali arasında ortalama $256 \mathrm{HV} 1$ ve ray metalinde ortalama $248 \mathrm{HV} 1$ olarak gözlemlenmiştir. Çekme testi sonuçlarına göre, termit kaynaklı rayın çekme numunesi kaynak merkezinden, yakma alın kaynaklı ray numunesi ise ITAB'ın hemen bitiminden kopmuştur. Hem termit hem de yakma alın kaynaklı ray malzemelerinin sünek bir davranış sergilediği gözlemlenmiştir. Kopma bölgelerinin kesitten alınan mikroyapı analizlerine göre, termit ve yakma alın kaynaklı raylardaki mikroyapıların büyük bir kısmında sementit ağı dağılımı gözlemlenmiş olup, kopma işlemi kırılganlığa neden olan yoğun sementit alanından olmuştur.

Anahtar kelimeler: Ray, Termit kaynağı, Yakma alın kaynağı, Mikroyapı, Mekanik özellikler

\section{Investigation of R260 Quality Rail Microstructure and Mechanical Properties Combined with Thermite and Flash Butt Welding}

\begin{abstract}
The aim of this study is to examine the microstructure and mechanical properties of thermite and flash butt rail welding methods, which are the two most common methods used in joining rails. The rail used in this study has EN 13674-1 standard, R260 quality, 60E1 profile and $1 \mathrm{~m}$ length. The rails with the specified features are combined with termite and flash butt-rail welding methods for the necessary work. Termite rail welding was built in TCDD DATEM and flash butt rail welding was done in TCDD Çankırı Scissor Factory. Residual stress, microstructure, hardness and tensile properties of post-weld thermite and flash butt rail welding, parts taken from rail cork were investigated. According to the residual stress results, the residual stress value of the original unwelded rail was $154 \mathrm{MPa}$, the residual stress value of the termite rail welding was $172 \mathrm{MPa}$ and the residual stress value of the flash butt rail welding was $160 \mathrm{MPa}$. According to the microstructure results, when the microstructure of the termite rail welding was examined, it was observed that the structure was ferrite and perlite but not martensite. When the microstructure of the flash butt rail weld was examined, it was observed that the structure was mostly perlitic with ferrite. According to the hardness test results, the hardness values in thermite rail welding were observed as an


average of $292 \mathrm{HV} 1$ in the weld center, an average of $310 \mathrm{HV} 1$ between the weld center and ITAB, an average of $308 \mathrm{HV} 1$ in the ITAB, an average of $264 \mathrm{HV} 1$ between the ITAB and the rail metal, and an average of $251 \mathrm{HV} 1$ in the rail metal. The hardness values in the flash butt rail welding were observed as an average of $296 \mathrm{HV} 1$ in the weld center, an average of $298 \mathrm{HV} 1$ between the welding center and ITAB, an average of $292 \mathrm{HV} 1$ in the ITAB, an average of $256 \mathrm{HV} 1$ between the ITAB and the rail metal, and an average of $265 \mathrm{HV} 1$ in the rail metal. According to the tensile test results, the tensile specimen of thermite rail weld broke from the weld center, and the flash butt rail weld specimen broke just after the end of the HAZ. It has been observed that both termite and flash head rail welding material exhibit a ductile behavior. According to the microstructure analyzes of the rupture regions taken from the cross-section, cementite network distribution was observed in most of the microstructures of thermite and flash butt welded rails, and the rupture process was from the dense cementite area that caused brittleness.

Keywords: Rail, Thermite welding, Flash butt welding, Microstructure, Mechanical properties

\section{Giriş}

Ray, demiryolu araçlarına düzgün bir yuvarlanma yüzeyi oluşturan, tekerlekleri yönlendiren, dingillerden gelen yüklerin traverslere aktarılmasını sağlayan, dökme çelikten imal edilen bir demiryolu üstyapı elemanıdır [1]. Rayın temel fonksiyonu yüklere dayanmak ve raylı taşıtların tekerleklerini yönlendirmektir [2]. Günümüzde çeşitli demiryollarında kullanılan ray türleri genellikle Vinyol ve oluklu raylardır [3]. Vinyol tipi bir ray mantar, gövde ve taban olmak üzere üç bölümden oluşur [4]. Ray çeliği çoğunlukla perlitik bir mikroyapıya sahip olup, ortalama $\% 0,8$ $\mathrm{C}$ ve aşınma özelliklerini iyileştirmesi amacı ile \%1 civarında mangan elementi içeren çelik kompozisyonunda üretilir $[2,5]$.

Demiryollarının başlangıcından günümüze kadar kaynaksız ray birleşim yerlerinin yol açtığı ray uçlarında ve raylı taşıtların tekerleklerinde çatlama, ezilme, ufalanma, kırılma vb. çeşitli sorunlar meydana gelmiştir. Bu sorunların çözümü için cebire kullanımı, conta boşluklarının optimize edilmesi vb. farklı yöntemler geliştirilmesine rağmen yeterli olmamıştır. Son olarak rayların kaynaklanması fikri ortaya atılarak raylarda ve raylı taşıtların tekerleklerinde meydana gelen sorunlar giderilmiştir [6].

Rayların birleştirilmesi kaynaksız ve kaynaklı olmak üzere iki çeşittir. Kaynaksız ray bağlantısı, cebire adı verilen genellikle delikli olan iki metal plakanın, cebire deliklerini karşılayacak biçimde delinen karşılıklı iki ray ucuna her iki taraftan cıvatalı bir şekilde bağlanması prensibine dayanır. Cebireli kaynaksız ray birleşiminde bakım-onarım masrafları, raylı taşıtlarının tekerlek hasarları ve güç tüketiminin artmasının yanı sıra demiryolu güvenliği ise azalmaktadır. Bunun gibi çeşitli olumsuzluklar nedeniyle kaynaksız ray bağlantısının günümüzde kullanım alanı daralmıştır [7]. Kaynaksız ray bağlantısındaki çeşitli problemlere çözüm olarak rayların kaynakla birleştirilmesi fikri ortaya atılmışır [8].

Rayların birleştirilmesinde kullanılan en yaygın iki yöntem termit ve yakma alın ray kaynaklarıdır $[9,10]$. Rayların kaynaklanması özellikle demiryolu bakım-onarım maliyetlerini azaltır, muayene işlemlerini kolaylaştııır, gürültü ve titreşimin kontrol altına alınmasını sağlar, demiryolu güvenliğini artırır, ağır yük taşımacılığı ve yüksek hızlara olanak sağlar [11].

Turan vd. [3], farklı tipteki raylarda gerinim ölçer ve X-1şını kırınım yöntemi ile kalıntı gerilimi ölçümü yapmışlardır. Turan [12], R260 kalite tren raylarında kalıntı gerilmenin belirlenmesi ve bunun mekanik özelliklere etkisini incelemiştir. Ilic vd. [9], raylarda kaynak sonrası 1sıl işlem görmüş termit kaynağının mikroyapısı ve mekanik karakterizasyonu incelemişlerdir. Rajanna vd. [11], 1sıl işlem görmüş termit kaynaklı ray çeliği ile tahliyenin mekanik davranışında iyileştirilmesini incelemişlerdir. Saita vd. [13], ray kaynağ1 teknolojilerindeki trendler ve gelecekteki yaklaşımlarını sunmuşlardır. Sidki vd. [14], ray ve termit kaynağı arasındaki mekanik davranışın ve mikroyapısal kıyaslamanın deneysel çalışmalarını yapmışlardır. Myers vd. [15], 
raydaki termit kaynaklarının yapısı ve özelliklerini incelemişlerdir. Mansouri vd. [16], yakma alın kaynaklı demiryollarının kaynak bölgesindeki mikroyapı ve kalıntı gerilme değişimlerini incelemişlerdir. Kuchuk-Yatsenko vd. [17], günümüz üretimi olan yüksek mukavemetli rayların yakma alın kaynă̆ını incelemiş̧lerdir. Porcaro vd. [18], yakma alın kaynaklı perlitik rayın mikroyapısı ve mekanik özelliklerini incelemişlerdir.

\section{Metot}

\subsection{Termit ray kaynăğ}

Termit ray kaynağı yöntemi, demir oksit ile alüminyum metalinin kimyasal reaksiyonu sonucu kaynak yapılacak iki ray arasına ergiyen çeliğin dökülmesi sonucu rayların kaynaklanmasına dayanır. Bu yöntem reaksiyon, döküm, soğutma, sıyırma ve taşlama işlemlerinden oluşur. $\mathrm{Bu}$ kaynak yönteminde kullanılan ekipmanlar ise ön 1sıtma firını, pota, kaynak seti, sıyırıcı ve taşlayıcıdır [19].

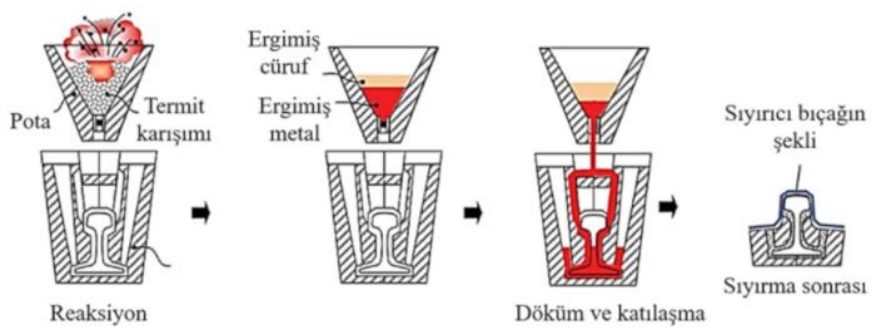

Şekil 1. Termit ray kaynağı prensibi [13]

Termit ray kaynağı genellikle alüminotermit ray kaynağı olarak da bilinmektedir. Ray kaynakları ve kırık rayların bakım-onarımında yaygın olarak kullanılmakta olup, manuel bir döküm yöntemidir $[10,20]$. Yakma alın ray kaynağına göre ucuz bir maliyete sahip olan termit ray kaynağı, yakma alın ray kaynağı uygulamasının mümkün olmadığı durumlarda kolaylıkla uygulanabilmektedir [9].

\subsection{Yakma alın ray kaynăğ}

Yakma alın ray kaynağı yöntemi, kaynaklanacak ray uçlarının elektrik yardımıyla 1sıtılıp ergitilerek birleştirilmesine dayanır. Ergiyene kadar 1sıtılan ray uçları daha sonra birbirine doğru basınç yardımıyla birleştirilir. Bu yöntem hizalama, ilk yanma, ön 1sıtma, yakma, basma-şişirme ve sıyırma işlemlerinden oluşur. Bu kaynak yönteminde kullanılan ekipmanlar ise transformatör, elektrotlar, basma ve hidrolik düzeltme aparatlarıdır [21].
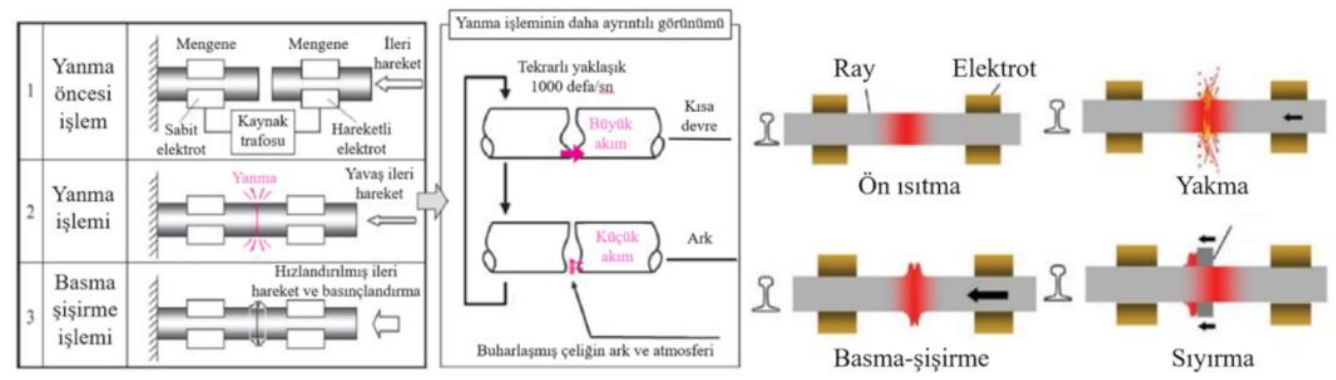

Şekil 2. Yakma alın ray kaynağı prensibi $[13,16]$ 
Dirençli kaynak işlemlerinden olan yakma alın ray kaynă̆ı, otomatik olarak uygulanmaktadır. Ayrıca bu kaynak yönteminde ek bir dolgu malzemesi kullanılmaması, yakma alın kaynaklı rayın, orijinal ray ile aynı yorulma ömrüne ulaşmasını sağlayabilmektedir $[9,16]$.

\section{Deneysel Çalışmalar}

\section{1. Çalışmada kullanılan rayın özellikleri}

Bu çalışmada kullanılan ray, EN13674-1 standartlı, 60E1 profilli ve R260 kaliteli raydır. Profil özellikleri itibariyle 60E1, 1 metre ağırlığ yaklaşık $60 \mathrm{~kg}$ ve kalite olarak R260 kaliteye sahiptir [5].

Tablo 1. Çalışmada kullanılan rayın kimyasal kompozisyonu [3]

\begin{tabular}{cccccccccc}
\hline Kalite & $\mathrm{C}$ & $\mathrm{Mn}$ & $\mathrm{Si}$ & $\mathrm{P}$ & $\mathrm{Cr}$ & $\mathrm{Ni}$ & $\mathrm{S}$ & $\mathrm{Al}$ & $\mathrm{Mo}$ \\
\hline R260 & 0,75 & 0,93 & 0,33 & 0,025 & 0,047 & 0,095 & 0,021 & 0,011 & 0,029 \\
\hline
\end{tabular}

Tablo 2. Çalışmada kullanılan rayın bazı mekanik özellikleri [22]

\begin{tabular}{ccc}
\hline $\begin{array}{c}\text { Minimum nihai çekme } \\
\text { dayanımı }(\mathrm{MPa})\end{array}$ & Minimum uzama (\%10) & $\begin{array}{c}\text { Yuvarlanma yüzeyi } \\
\text { merkezinin sertliği (HBW) }\end{array}$ \\
\hline 880 & 10 & $260 / 300$ \\
\hline
\end{tabular}

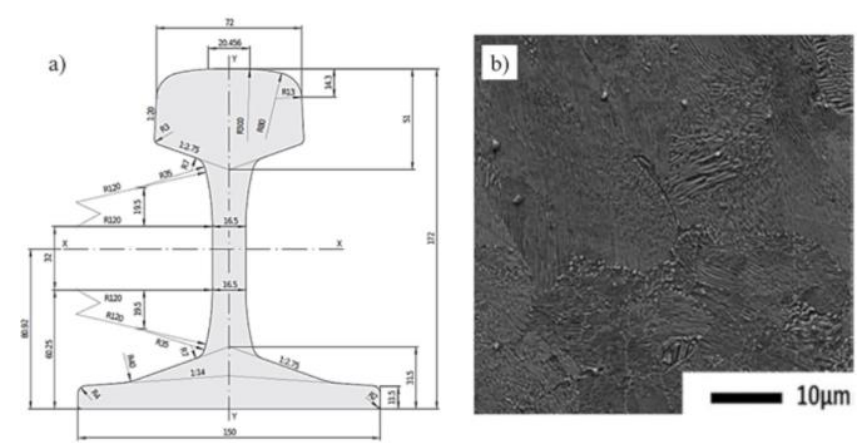

Şekil 3. Çalışmada kullanılan a) ray profili [23] ve b) mikroyapısı [3]

\subsection{Kalıntı gerilme testi}

Kalıntı gerilme testleri, Karabük Üniversitesi Demir Çelik Enstitüsü Kalıntı Gerilme Ölçme Laboratuvarında yapılmıştır. Kullanılan cihaz Vishay System 7000 Veri Toplama Cihazıdır.

Kalıntı gerilmeler, kesme yöntemiyle hazırlanan numunelerin ortasına yapıştıılan Strain gauge vasıtasıyla ölçülmüştür. Ray, kesme testeresine bağlandığında kesme testeresi rayları Strain gauge'lerin her iki tarafından $10 \mathrm{~mm}$ uzağa kesmiştir. Strain gauge konumu ve testere kesim yerleri Şekil 4, özellikleri ise Tablo 3'te verilmiştir.

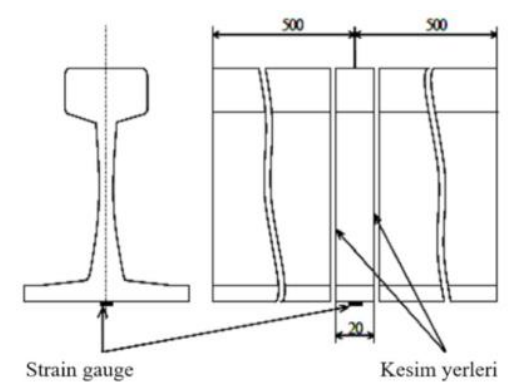

Şekil 4. Strain gauge konumu ve kesim yerleri [1] 
Tablo 3. Strain gauge özellikleri [1]

\begin{tabular}{cc}
\hline Strain gauge uzunluğu & $3 \mathrm{~mm}$ \\
Strain gauge direnci & $350 \Omega$ \\
Gauge faktörü & 2,11 \\
\hline
\end{tabular}

\subsection{Mikroyapı çalışmaları}

Mikroyapı çalışmaları, Karabük Üniversitesi Demir Çelik Enstitüsü Metalografi Laboratuvarında yapılmıştır. Mikroyapı ölçüm cihazının adı Nikon Ters Metalürjik Mikroskop olup, 50x-100x200x-500x-1000x büyütme özelliğine sahiptir.

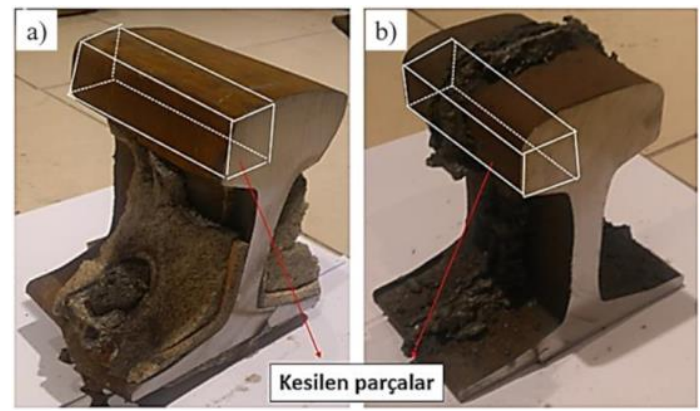

Şekil 5. Mikroyapı ve sertlik için kesilen a) termit ve b) yakma alın ray kaynağı numune parçaları [24]

Mikroyapı ve sertlik testi çalışmaları için öncelikle termit ve yakma alın kaynaklı raylar Şekil 5'te gösterildiği gibi kesilmiştir. Daha sonra gerekli çalışmalar için kesilen numuneler Şekil 6'daki gibi bakalite alınarak numunelerin kaynak merkezi, geçiş bölgesi (ITAB) ve ray metali incelenmiştir. Termit ray kaynağının kaynak bölgesi, yakma alın ray kaynağına göre daha büyük olup, tek bakalite sığmadığından iki bakalit alınarak incelenmiştir.
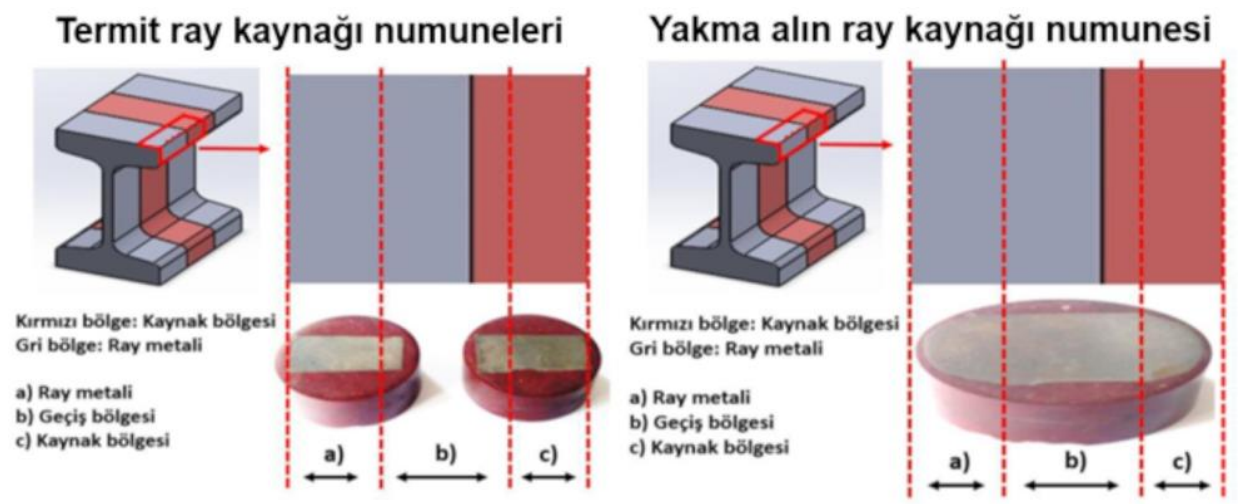

Şekil 6. Termit ve yakma alın kaynaklı rayların bakalitleri [24]

\subsection{Sertlik testi}

Sertlik testleri, Karabük Üniversitesi Teknoloji Fakültesi Mekanik Testler Laboratuvarında yapılmıştır. Sertlik testi ölçüm cihazının adı Shimadzu HMV-G Mikro Vickers’tir.

Sertlik testleri, mikroyapı incelemelerinin yapıldığı bakalit üzerinden gerçekleştirilmiştir. Sertlik, Vickers olarak ölçülmüş olup, HV1 sertlik ölçeği kullanılmıştır. Ayrıca ölçümde kullanılan yük $10 \mathrm{~N}$ olup, $10 \mathrm{sn}$. boyunca uygulanmıştır. Ölçüm uzaklığı, kaynak merkezinden başlamak üzere sırasıyla ITAB (geçiş) ve son olarak ray metali bölgeleri şeklindedir. 


\section{5. Çekme testi}

Çekme testleri, Karabük Üniversitesi Demir Çelik Enstitüsü Statik Test Laboratuvarında yapılmıştır. Çekme testi cihazı Zwck/Roell Z600 Çekme-Basma-Eğme Testleri Cihazı olup, 600 $\mathrm{kN}$ yük uygulayabilmekte ve çeşitli aparatlar vasıtasıyla çekme, basma ve eğme testlerini yapabilmektedir.

Çekme testleri DIN EN ISO 6892-1 standardına sahiptir. Çekme numuneleri termit ve yakma alın ray kaynağı için aynı ölçülerde olup, Şekil 7'deki gibi numunenin merkezi ve kaynak merkezinin ortasından oluşmaktadır. Numuneler hem termit hem de yakma alın kaynaklı rayın mantarından üçer adet yaptırılmıştır. Test sonuçları, testleri yapılan üçer numuneden elde edilen sonuçların ortalamalarından oluşmaktadır.
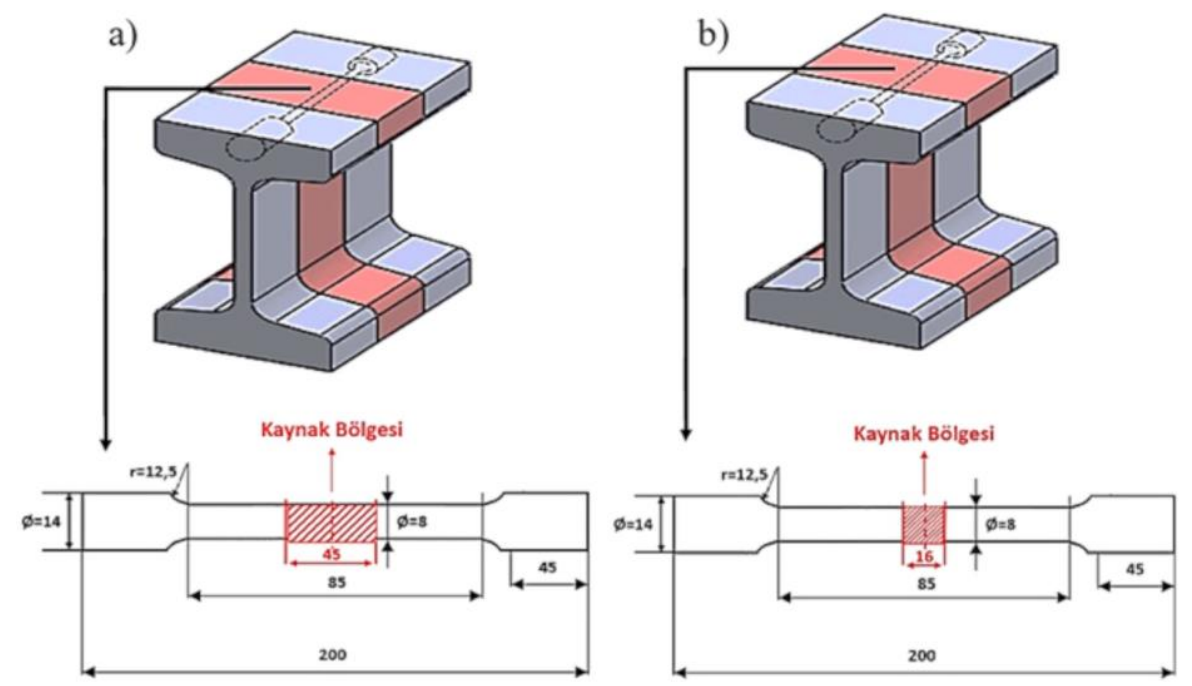

Şekil 7. a) Termit ve b) yakma alın ray kaynağından çekme testi numunelerinin çıkarılması [24]

\section{Bulgular}

\subsection{Kalınt gerilme testi}

Hazırlanan ray numunelerine iki adet kesme işlemi uygulanmış ve Strain Smart yazılım programı kullanılarak gerinim değerleri elde edilmiştir. Kalıntı gerilme değerleri Hooke Kanunu'na göre birinci ve ikinci kesme değerleri arasındaki farkın $2,07 \times 10^{5} \mathrm{MPa}$ ile çarpılmasıyla hesaplanmıştır [12].

Tablo 4. Orijinal, termit ve yakma alın kaynaklı rayların kalıntı gerilmelerinin test sonuçları [24]

\begin{tabular}{ccc}
\hline Numune & Gerinim $(\mu \mathrm{m} / \mathrm{m})$ & Gerilim $(\mathrm{MPa})$ \\
\hline R260 kalite orijinal ray & 743 & 154 \\
Termit kaynaklı ray & 830 & 172 \\
Yakma alın kaynaklı ray & 772 & 160 \\
\hline
\end{tabular}

Tablo 4'te yer alan kalıntı gerilme testi ölçüm sonuçlarına göre R260 kalite ray en düşük kalıntı gerilmeye, yakma alın kaynaklı ray ikincil kalıntı gerilmeye ve termit kaynaklı ray ise en yüksek kalıntı gerilmeye sahip olduğu bulunmuştur. Genel olarak R260, termit ve yakma alın kaynaklı raylar arasında oluşan kalıntı gerilme farklarının sıcaklık ve soğumadan kaynaklandığı söylenebilir. Ölçüm sonuçlarına göre elde edilen kalıntı gerilme değerleri, demiryolu standartlarına göre belirlenen $250 \mathrm{MPa}$ maksimum kalıntı gerilme değerinden düşük olup, kabul edilebilir ölçüm değerindedir [24]. Kalıntı gerilme sonuçları literatür [3, 12] ile benzerlik göstermektedir. 


\subsection{Mikroyapı çalışmaları}

Şekil 8'de termit ray kaynağı, Şekil 9'da ise yakma alın ray kaynağı numunelerinin kaynak merkezi, ITAB ve kaynak metalinin mikroyapıları verilmiştir.

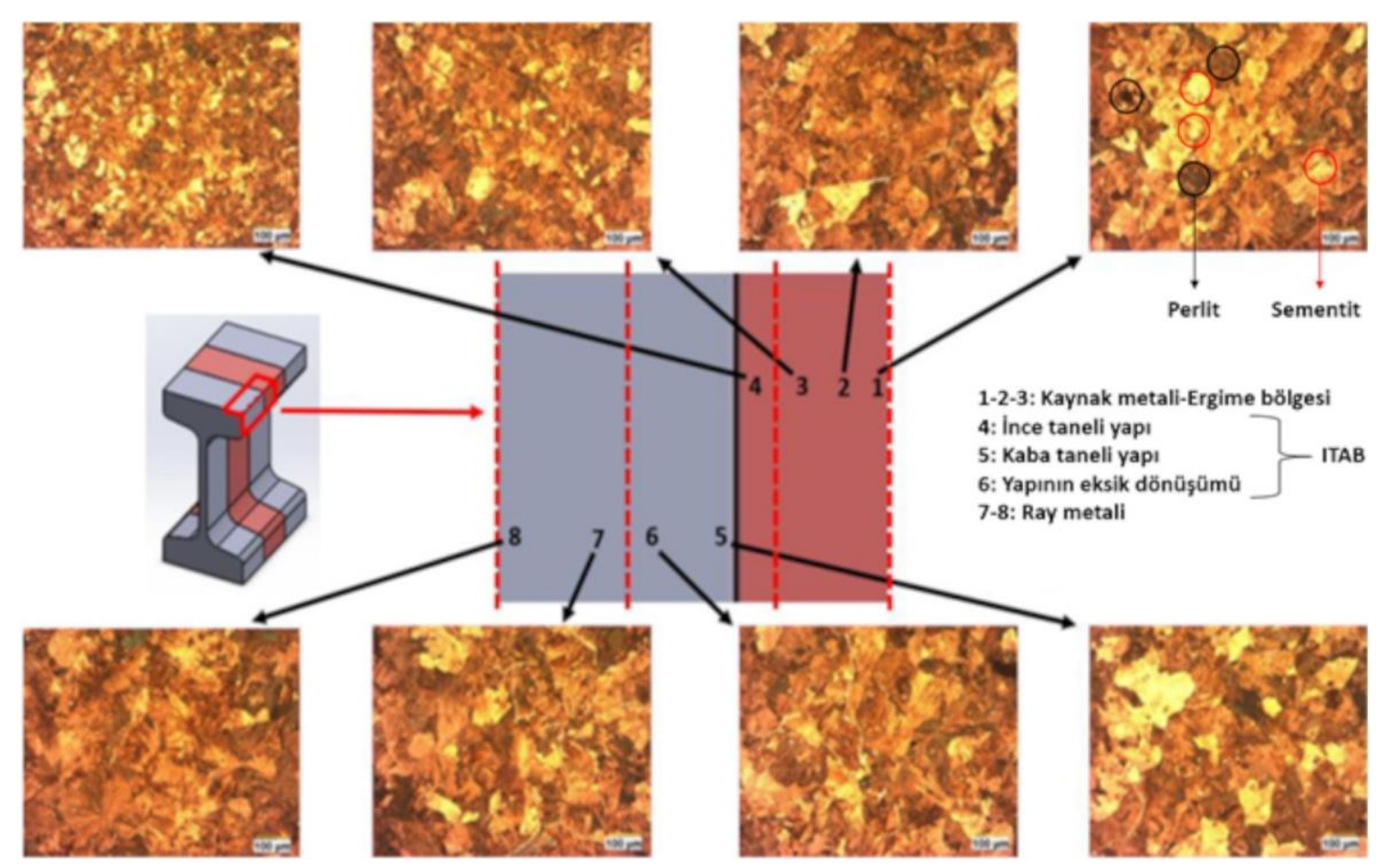

Şekil 8. Termit kaynaklı rayın kaynak metali, ITAB ve ray metalinin mikroyapısı $(100 \mu \mathrm{m})$ [24]

Şekil 8'deki termit kaynaklı rayın kaynak merkezindeki mikroyapı incelendiğinde, merkezde sementit $\left(\mathrm{Fe}_{3} \mathrm{C}\right)$ taneleri ile ferrit $\left(\mathrm{Fe}_{\infty}\right)$ taneleri gözlenir. Kaynak merkezinde sementit alanları daha fazladır ve sementit alanlarının fazlalığı kaynak merkezini kırılgan yapmaktadır. Kaynak merkezinden ITAB'a doğru gidildikçe ferrit oranının arttı̆̆ 1 ve sementit oranının ise azaldığ gözlenir. $\mathrm{Bu}$ durum, kimyasal içerikteki $\mathrm{Mn}$ ve $\mathrm{Si}$ elementlerinin döküm çeliği kalitesini iyileştirmesinden ve sıcaklıktan kaynaklanır [24].

ITAB (geçiş bölgesi) incelendiğinde, ITAB başlangıcındaki mikroyapının dağılmış ferrit ile sementit tanelerinden oluştuğu gözlenir. ITAB merkezindeki mikroyapıda sementit oranının ferrit oranına göre daha fazla olduğu gözlenir. Bu durum, sıcaklığın etkisinden kaynaklanır. ITAB sonuna doğru yapıdaki sementit dağılımı azalır ve ferrit oranı ise artar. Bu durum, soğuma hızının azalmasından kaynaklanır [24].

Ray metali mikroyapısı incelendiğinde, ray metalinin ITAB'a yakın alanlarında ferrit oranının bir miktar arttığı gözlenir. Bu durum, 1sının etkisinden kaynaklanır. Ray metalindeki mikroyapının ise ince taneli perlitik olduğu gözlemlenmiştir. Bu yapı, yüksek bir çekme dayanımı ve kopma uzamasina sahiptir [24].

Mikroyapı genel olarak incelendiğinde, yapının ferrit ve perlit $\left(\mathrm{Fe}_{\infty}+\mathrm{Fe}_{3} \mathrm{C}\right)$ içerip, martenzit içermediği gözlemlenmiştir [24]. Mikroyapı sonuçları literatür [9, 11, 13, 14] ile benzerlik göstermektedir. 


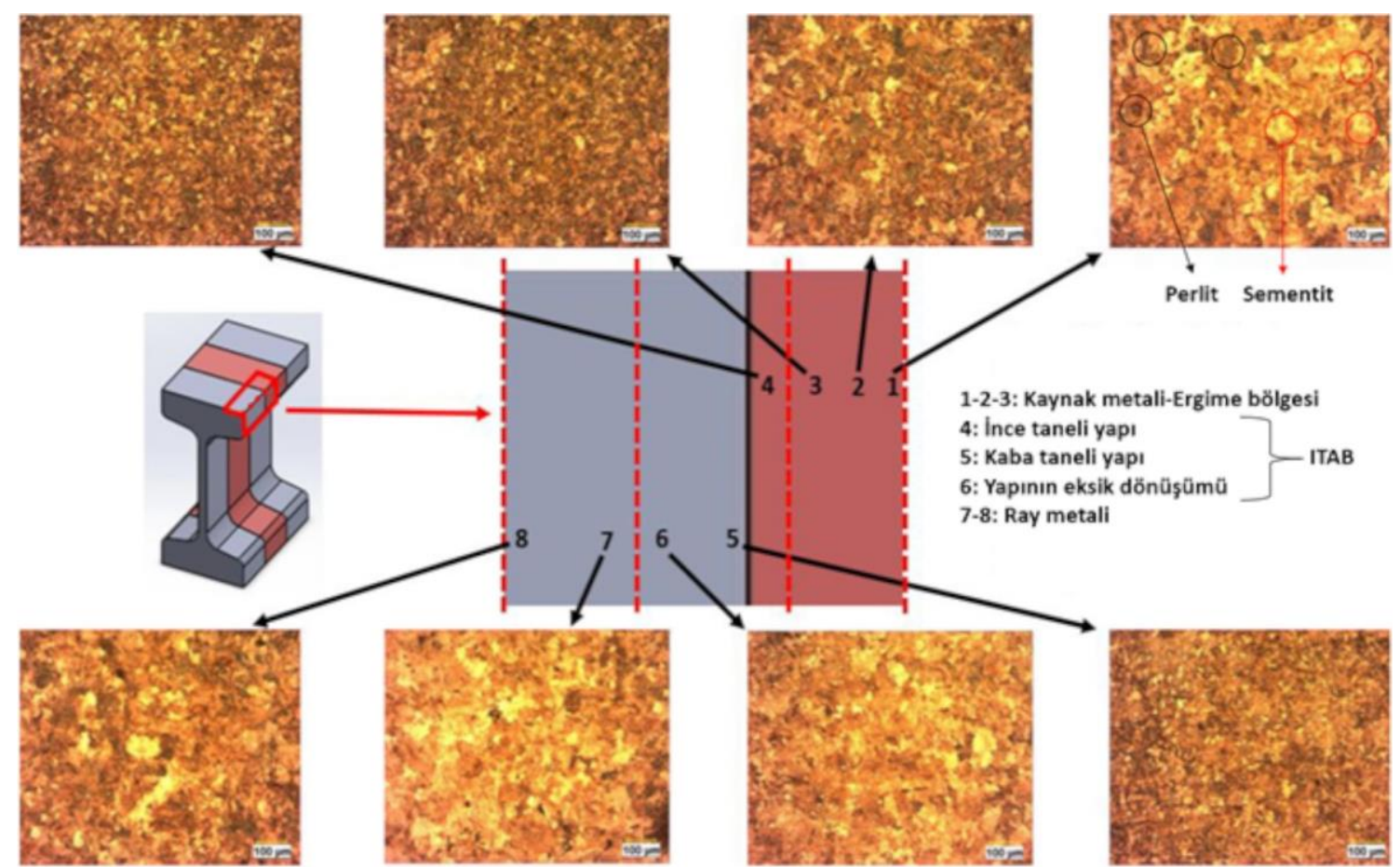

Şekil 9. Yakma alın kaynaklı rayın kaynak metali, ITAB ve ray metalinin mikroyapısı $(100 \mu \mathrm{m})[24]$

Şekil 9'daki yakma alın kaynaklı rayın kaynak merkezindeki mikroyapı incelendiğinde, merkezde dağılmış sementit taneleri ile ferrit taneleri gözlemlenmiştir. Kaynak merkezinden ITAB'a doğru gidildikçe sıcaklığın azalmasıyla ssıl parametrelerin etkisinden sementit tanelerinin azaldığı ve ferrit tanelerinin arttığı gözlemlenmiştir. ITAB'a yakın alanlarda soğumaya ve sıcaklığın azalmasına bağlı olarak ince taneli perlitik yapı gözlemlenmiştir [24].

ITAB (geçiş bölgesi) incelendiğinde, ITAB başlangıcındaki mikroyapının küçük alanlı ve ince taneli ferrit ile sementitten oluştuğu gözlemlenmiştir. ITAB merkezinde sementit tanelerinin büyüdüğü ve ferritik alanların küçüldüğü gözlemlenmiştir. ITAB sonuna doğru sıcaklığın etkisinden dolayı sementit tanelerinin büyüdüğü, ferrit tanelerinin ise küçüldüğ̈̈ gözlemlenmiştir. Bu durum, ani soğuma ve sıcaklığın azalmasından kaynaklanmaktadır [24].

Ray metalinin ITAB'a yakın alanları incelendiğinde, ITAB'ın etkisindeki bölgede mikroyapıda artan sementit alanlarının ve azalan ferritik tanelerin oluşumu gözlenmiştir. Bu durum, 1sının etkisinden kaynaklanmaktadır. Ray metalindeki mikroyapı ise daha fazla ferritik tanelerden ve çok az miktarda sementit lamellerinden oluşmaktadır [24].

Mikroyapı genel olarak incelendiğinde, yapının ferrit ve perlit içerdiği gözlemlenmiştir [24]. Mikroyapı sonuçları literatür $[16,17,18]$ ile benzerlik göstermektedir.

\subsection{Sertlik testi}

Şekil 10'da termit ve yakma alın kaynaklı ray numunelerinin $10 \mathrm{~N}$ yük altında Vickers sertlik ölçüm yöntemiyle ölçülen sertlik sonuçları verilmiştir. 


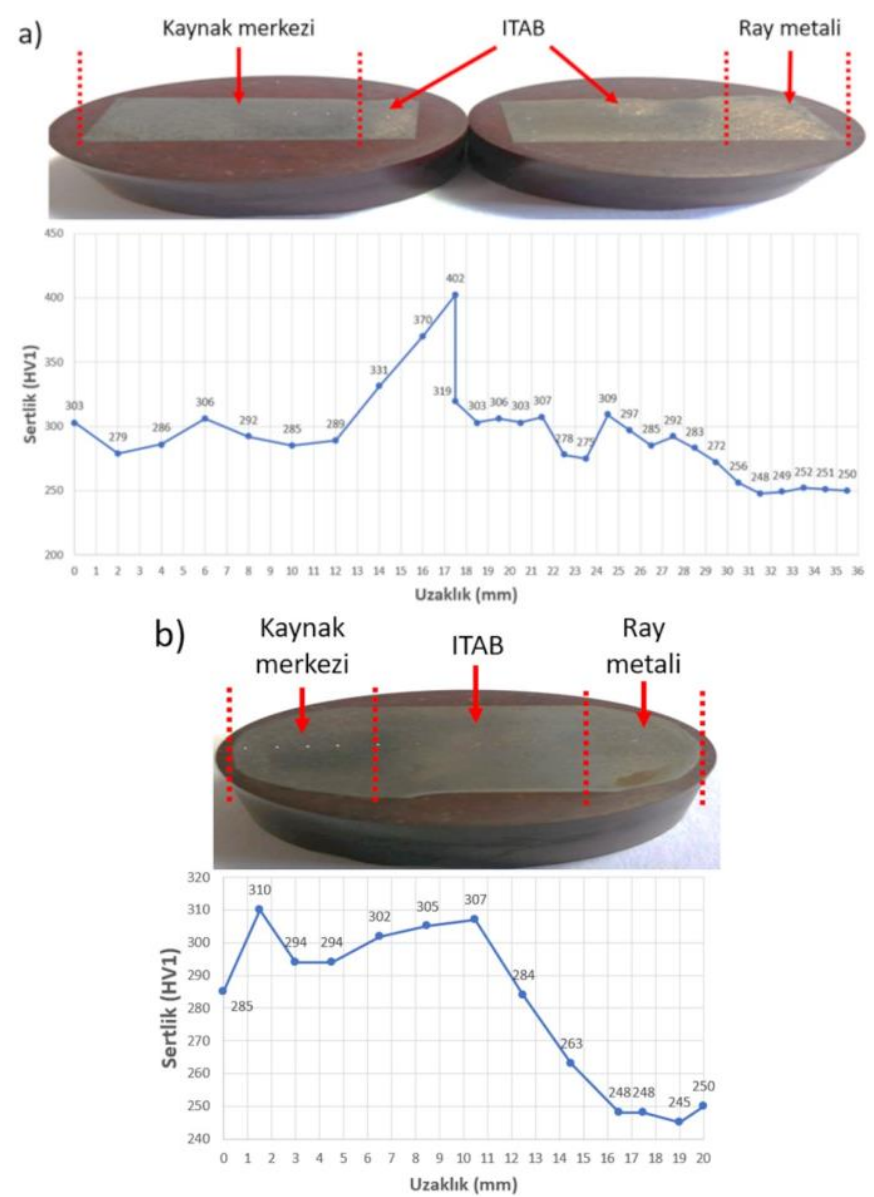

Şekil 10. a) Termit ve b) yakma alın kaynaklı rayların sertlik grafikleri [24]

Termit kaynaklı rayın sertlik profili incelendiğinde, kaynak merkezindeki sertlik ortalama 292 HV1, kaynak merkezi ile ITAB arasinda ortalama 310 HV1, ITAB'da ortalama 308 HV1, ITAB ile ray metali arasında ortalama $264 \mathrm{HV} 1$ ve ray metalinde ortalama 251 HV1 olarak gözlemlenmiştir. Maksimum sertlik değeri ITAB'da, minimum sertlik değeri ise ray metalinde bulunmuştur. Simetrik olmayan sertlik grafiği genelde kaynak metalinin katılaşması sırasında alüminotermit kaynağın ani ve homojen olmayan soğumasından kaynaklanır [24]. Termit kaynaklı rayın sertlik sonuçları literatür $[9,11,13,14]$ ile benzerlik göstermektedir.

Yakma alın kaynaklı rayın sertlik profili incelendiğinde, kaynak merkezindeki sertlik ortalama 296 HV1, kaynak merkezi ile ITAB arasinda ortalama 298 HV1, ITAB'da ortalama 292 HV1, ITAB ile ray metali arasinda ortalama $256 \mathrm{HV} 1$ ve ray metalinde ortalama 248 HV1 olarak gözlemlenmiştir. Maksimum sertlik değeri kaynak merkezinde, minimum sertlik değeri ise ray metalinde bulunmuştur. ITAB ile ray metaline geçişte sertlikte ani bir düşüş vardır. Literatürde bu bölge, yumuşatılmış bölge olarak adlandırılır. Yakma alın kaynağında genelde kaynak ile ısıdan etkilenen bölgedeki sertlik değişimi önemli değildir [24]. Yakma alın kaynaklı rayın sertlik sonuçları literatür $[16,17,18]$ ile benzerlik göstermektedir. 


\section{4. Çekme testi}

Şekil 11'de Termit ve yakma alın kaynaklı ray numunelerinin çekme testi grafiği yer almaktadır.

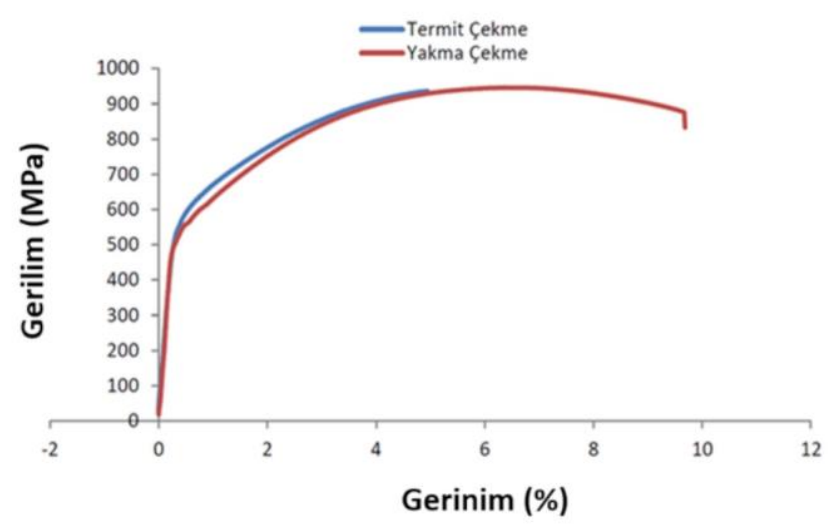

Şekil 11. Termit ve yakma alın kaynaklı rayların çekme grafiği [24]

Belirgin akma göstermeyen bir çekme testi grafiğinde \%0,2 uzamasına karş1lık gelen gerilmeye akma dayanımı denir. Termit kaynaklı ray numunesinin çekme testi grafiğine bakıldığında, akma dayanımı başlangıcı yaklaşık $550 \mathrm{MPa}$ 'dan başlamaktadır. Uzama durumunda yaklaşık $900 \mathrm{MPa}$ gerilim etkisi altında uygun gelen gerilme çekme gerilmesidir. Çekme gerilmesine karşılık gelen uzama \%5 değerindedir. Numune \%0,5-5 uzama oranındaki aralığında sünek bir davranış sergilemiştir. Ayrıca numunenin kopma büzülmesi düşüktür [24].

Yakma alın kaynaklı rayın çekme testi grafiğgine bakıldığında, akma dayanımı başlangıcı yaklaşık $600 \mathrm{MPa}$ 'dan başlamaktadır. Uzama durumunda yaklaşı $900 \mathrm{MPa}$ gerilimin etkisi altında karşılık gelen gerilme çekme gerilmesidir. Çekme gerilmesine karşıllk gelen uzama yaklaşık $\% 9,5$ değerindedir [24].

Yakma alın kaynaklı rayın çekme grafiği, termit kaynaklı rayın çekme grafiğine göre kıyaslandığında tokluk, kopma uzaması, plastik deformasyon ve kopma büzülmesinin daha fazla olduğu söylenebilir [24]. Çekme testi sonuçları literatür [11, 18] ile benzerlik göstermektedir.

\subsection{Kopma bölgesi kesiti mikroyapı analizi}

Şekil 12'de termit ve yakma alın kaynaklı ray numunelerinin çekme testi öncesi ve sonrası fotoğrafları, Şekil 13'te ise termit ve yakma alın kaynaklı ray numunelerinin çekme testi sonucundaki kopma bölgelerinin kesitinden alınan mikroyapılar verilmiştir.
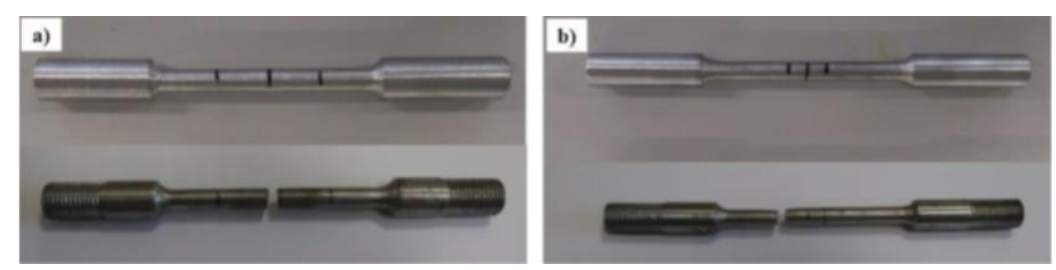

Şekil 12. a) Termit ve b) yakma alın kaynaklı ray numuneleri çekme testi önce ve sonrası fotoğrafları [24] 
Çekme testi sonuçlarına göre, termit kaynaklı rayın çekme numunesi kaynak merkezinden, yakma alın kaynaklı ray numunesi ise ITAB'ın hemen bitiminden kopmuştur [24].
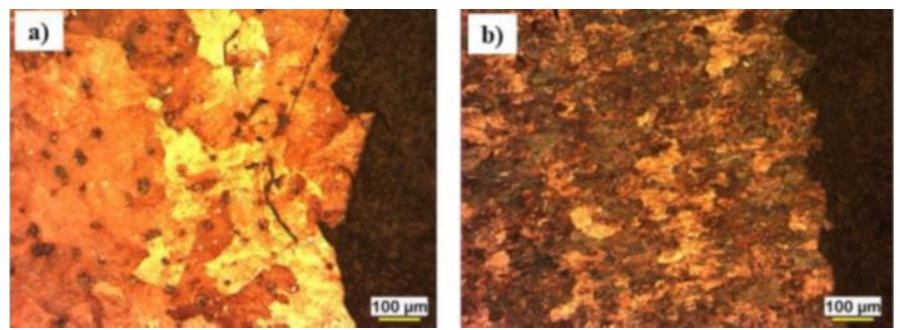

Şekil 13. a) Termit ve b) yakma alın kaynaklı rayların çekme testi sonrası kopma bölgesi kesitinden alınan mikroyapıları [24]

Termit kaynaklı rayın çekme numunesine ait kopma bölgesi kesiti mikroyapısı incelendiğinde, yapının büyük bir kısmında sementit ağı dağılımı gözlenir. Geriye kalan alanlar ise ferrit tanelerinden oluşur. Yapıya genel olarak bakıldığında yapının sertliği sementit ağıyla alakalı olarak kırılgandır. Kopma, sementit ağına yakın yerlerden olmuştur [24].

Yakma alın kaynaklı rayın çekme numunesine ait kopma bölgesi kesiti mikroyapısı incelendiğinde, yapıda dağılan sementit alanlarının yoğunluğunun fazla olduğu görülmektedir. Sementit alanlarının fazlalığı kırılganlığa neden olmaktadır. Kırılganlık, kopmanın en büyük nedenlerinden biridir ve kopma ile doğru orantılıdır. Kopma, beklenildiği üzere kırılganlığın artmasına neden olan yoğun sementit alanından olmuştur [24]. Çekme numunelerinin koptuğu yerler ve kopma bölgesi mikroyapı analizleri literatür $[11,15]$ ile benzerlik göstermektedir.

\section{Sonuç}

1. Kalıntı gerilme sonuçlarına göre, termit kaynaklı rayın kalıntı gerilme değeri $172 \mathrm{MPa}$, yakma alın kaynaklı rayın kalıntı gerilme değeri $160 \mathrm{MPa}$ ve orijinal kaynaksız rayın kalıntı gerilme değeri $154 \mathrm{MPa}$ olarak bulunmuştur.

2. Mikroyapı sonuçlarına göre, termit kaynaklı rayın mikroyapısı incelendiğinde, yapının ferrit ve perlit olup, martenzit olmadığı gözlemlenmiştir. Yakma alın kaynaklı rayın mikroyapısı incelendiğinde, yapının çoğunlukla ferrit ile perlitik olduğu gözlemlenmiştir.

3. Sertlik testi sonuçlarına göre, termit kaynaklı rayın sertlik değerleri kaynak merkezinde ortalama 292 HV1, kaynak merkezi ile ITAB arasinda ortalama 310 HV1, ITAB'da ortalama 308 HV1, ITAB ile ray metali arasinda ortalama $264 \mathrm{HV} 1$ ve ray metalinde ortalama $251 \mathrm{HV} 1$ olarak gözlemlenmiştir. Yakma alın kaynaklı rayın sertlik değerleri, kaynak merkezinde ortalama 296 HV1, kaynak merkezi ile ITAB arasinda ortalama 298 HV1, ITAB'da ortalama 292 HV1, ITAB ile ray metali arasinda ortalama $256 \mathrm{HV} 1$ ve ray metalinde ortalama 248 HV1 olarak gözlemlenmiştir.

4. Çekme testi sonuçlarına göre, termit kaynaklı rayın çekme numunesi kaynak merkezinden, yakma alın kaynaklı rayın numunesi ise ITAB'ın hemen bitiminden kopmuştur. Hem termit hem de yakma alın kaynaklı ray malzemelerinin sünek bir davranış sergilediği gözlemlenmiştir.

5. Kopma bölgelerinin kesitten alınan mikroyapı analizlerine göre, termit ve yakma alın kaynaklı raylardaki mikroyapıların büyük bir kısmında sementit ağı dağılımı gözlemlenmiş olup, kopma işlemi kırılganlığa neden olan yoğun sementit alanından olmuştur. 


\section{Kaynakça}

[1] E. Turan, M. Dursunlar and H. Çuğ, "Investigation of welding residual stress in flash-butt joint of R260 grade rail," Fourth International Railway Systems Symposium (ISERSE'18), Karabük, Türkiye, 2018, pp. 735-733.

[2] M. Saarna and A, Laansoo, "Rail and rail weld testing," 4th International DAAAM Conference, 2004, pp. 217-219.

[3] E. Turan, F. Aydın, Y. Sun and M. Çetin, "Residual stress measurement by strain gauge and X-ray diffraction method in different shaped rails," Engineering Failure Analysis, vol. 96, pp. 525-529, October, 2018, doi: 10.1016/j.engfailanal.2018.10.016.

[4] H. Çuğ, E. Turan and M. Dursunlar, "Effect of termite welding process on residual stress, and wear behaviour of R260 quality rail," Fourth International Iron and Steel Symposium (UDCS'19), Karabük, Türkiye, 2019, pp. 533-535.

[5] O. Agin, "Hızlı tren hatlarında yeni ray profili", Demiryolu Mühendisliği, vol. 6, pp. 27-33, 2017.

[6] H.K. Jun, J.W. Seo, I.S. Jeon, S.H. Lee and Y.S. Chang, "Fracture and fatigue crack growth analyses on a weld-repaired railway rail," Engineering Failure Analysis, vol. 59, pp. 478-492, January, 2016, doi: 10.1016/j.engfailanal.2015.11.014.

[7] A.S.J.A.Z. Jilabi, "Welding of Rail Steels," PhD dissertation, Dept. School of Materials, University of Manchester, 2015.

[8] M. Jezzini-Aouad, P. Flahaut, S. Hariri and L. Winiar, "Improving fatigue performance of rail thermite welds," 14 ${ }^{\text {th }}$ International Conference on Experimental Mechanics (ICEM’14), Poitiers, France, 2010, pp. 07005, doi: 10.1051/epjconf/20100607005.

[9] N. Ilic, M.T. Jovanovic, M. Todorovic, M. Trtanj and P. Saponjic, "Microstructure and mechanical characterization of postweld heat-treated thermite weld in rails," Materials Characterization, vol. 43, no. 4, pp. 243-250, 1999, doi: 10.1016/S1044-5803(99)00006-6.

[10] C.P. Lonsdale, "Thermite rail welding: history, process developments, current practices and outlook for the 21st century," American Railway Engineering and Maintenance-of-Way Association (AREMA) Annual Conferences 2, America, 1999.

[11] S. Rajanna, H.K. Shivanand and B.N. Akash Deep, "Improvement in mechanical behavior of expulsion with heat treated thermite welded rail steel," World Academy of Science, Engineering and Technology International Journal of Mechanical and Mechatronics Engineering, vol. 43, no. 12, 2009.

[12] M.E. Turan, "R260 kalite tren raylarında kalıntı gerilmenin belirlenmesi ve bunun mekanik özelliklere etkisinin incelenmesi," M.Sc. dissertation, Dept. Metallurgy and Materials Eng., Karabük Univ., 2015.

[13] K. Saita, M. Ueda, T. Yamamoto, K. Karimine, K. Iwano and K. Hiroguchi, "Trends in rail welding technologies and our future approach," Nippon Steel \& Sumitomo Metal Technical Report, no. 105, December, 2013.

[14]F. Sidki, I. Mouallif, A.E. Amri, M. Boudlal and A. Benali, "Experimental study of mechanical behavior and microstructural benchmarking between the rail and the thermite weld," International Journal of Engineering Research and Development, vol. 6, no. 9, pp. 53-58, April, 2018.

[15] J. Myers, G.H. Geiger and D.R. Poirier, "Structure and properties of thermite welds in rail," Welding Journal, vol. 61, no. 8, pp. 258-268, 1982.

[16] H. Mansouri and A. Monshi, "Microstructure and residual stress variations in weld zone of flash-butt welded railroads," Science and Technology of Welding and Joining, vol. 9, no. 3, pp. 237-245, 2013, doi: 10.1179/136217104225012201.

[17] S.I. Kuchuk-Yatsenko, A.V. Didkovsky, V.I. Shvets, P.M. Rudenko and E.V. Antipin, "Flash butt welding of high-strength rails of nowadays production," The Paton Welding Journal, no. 5-6, pp. 412, 2016, doi: 10.15407/tpwj2016.06.01.

[18]R.R. Porcaro, G.L. Faria, L.B. Godefroid, G.R. Apolonio, L.C. Candido and E.S. Pinto, "Microstructure and mechanical properties of a flash butt welded pearlitic rail," Journal of Materials Processing Technology, vol. 270, pp. 20-27, 2019, doi: 10.1016/j.jmatprotec.2019.02.013.

[19] A. Skyttebol, B.L. Josefson and J.W. Ringsberg, "Fatigue crack growth in a welded rail under the influence of residual stresses," Engineering Fracture Mechanics, vol. 72, no. 2, pp. 271-285, January, 2005, doi: 10.1016/j.engfracmech.2004.04.009.

[20] A. Khodabakhshi, A. Paradowska, R. Ibrahim and P. Mutton, "Measurement of residual stresses in aluminothermic rail welds using neutron diffraction technique," Materials Science Forum, vol. 777, pp. 237-242, 2014, doi: 10.4028/www.scientific.net/MSF.777.237.

[21] M. Fujii, H. Nakanowatari and K. Nariai, "Rail flash butt welding technology," JFE Technical Report, no. 20 , pp. 159-163, 2015. 
[22] D.F. Cannon, K.O. Edel, S.L. Grassie and K. Sawley, "Rail defects: an overview," Fatigue Fracture Engineering Materials Structure, vol. 26, no. 10, pp. 865-886, June, 2003, doi: 10.1046/j.14602695.2003.00693.x.

[23] R. Ferrera, "A numerical model to predict train induced vibrations and dynamic overloads," Ph.D. dissertation, Dept. Marine, Materials and Structural Eng., University of Montpellier, 2014.

[24] M. Dursunlar, “Termit ve yakma alın kaynağ i ile birleştirilmiş R260 kalite rayın mikroyap1 ve mekanik özelliklerinin incelenmesi,” M.Sc. dissertation, Dept. Mech. Eng., Karabük Univ., 2019.

\section{Özgeçmiş}
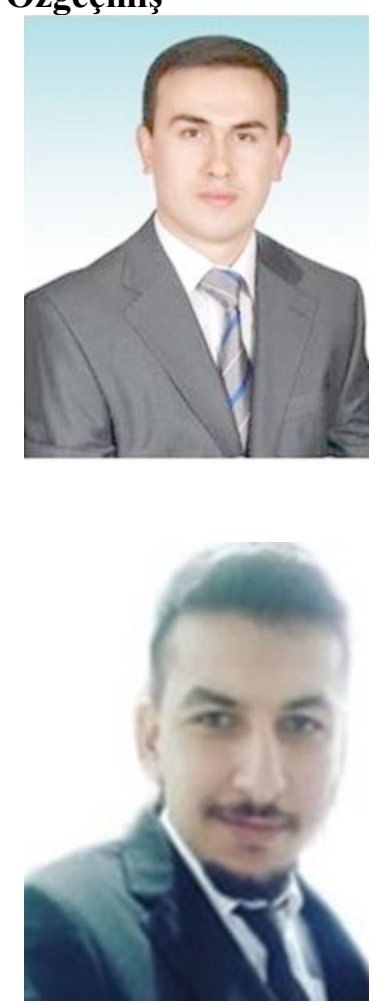

Beyanlar:

Bu makalede bilimsel araștırma ve yayın etiğine uyulmuștur.

Tüm yazarların eşit oranda katkısı olmuştur.

\section{Harun ÇŬ}

1981 yılında Karabük'te doğmuştur. 2005 yılında ZKÜ, Karabük Teknik Eğitim Fakültesi Metal Öğretmenliği programından, 2009 yılında Karabük Üniversitesi Fen Bilimleri Enstitüsü Metal Eğitimi Anabilim Dalı yüksek lisans programından mezun olmuştur. 2016 yılında Karabük Üniversitesi Fen Bilimleri Enstitüsü Metalürji ve Malzeme Mühendisliği Anabilim Dalında Doktor unvanını almıştır. 2009 yılında başladığı Akademik hayatına halen Karabük Üniversitesi Makine Mühendisliği bölümünde devam etmektedir. Evli ve 2 çocuk babasıdır.

E-Posta: hcug@karabuk.edu.tr

\section{Mustafa DURSUNLAR}

1993 y1lında Zonguldak'ta doğmuştur. Lisans ve yüksek lisans eğitimini Karabük Üniversitesi Makine Mühendisliği bölümünde tamamlamış olup, doktora eğitimine de aynı üniversite ve alanda devam etmektedir. Yozgat Bozok Üniversitesi Sorgun Meslek Yüksekokulunda öğretim görevlisi olarak çalışmaktadır. E-Posta: mustafa.dursunlar@yobu.edu.tr 